\title{
Effectiveness of Talc Filler on Thermal Resistance of Recycled PET Blends
}

\author{
Kazushi Yamada $^{1^{*}}$, Supaphorn Thumsorn ${ }^{2}$ \\ ${ }^{1}$ Kyoto Institute of Technology, Kyoto, Japan \\ ${ }^{2}$ Rajamangala University of Technology Thanyaburi, Pathum Thani, Thailand \\ Email: *kazushi@kit.ac.jp
}

Received October 27, 2013; revised November 28, 2013; accepted December 12, 2013

Copyright (c) 2013 Kazushi Yamada, Supaphorn Thumsorn. This is an open access article distributed under the Creative Commons Attribution License, which permits unrestricted use, distribution, and reproduction in any medium, provided the original work is properly cited. In accordance of the Creative Commons Attribution License all Copyrights (C) 2013 are reserved for SCIRP and the owner of the intellectual property Kazushi Yamada, Supaphorn Thumsorn. All Copyright (C) 2013 are guarded by law and by SCIRP as a guardian.

\begin{abstract}
In general, high mechanical properties such as higher impact strength and thermal resistance are required for injection molded applications. Recycled PET (RPET) is well known to exhibit brittle behavior in the presence of notches and indicated the low heat distortion temperature. Therefore, we tried to improve the toughness and thermal resistance properties of RPET by incorporating E-GMA, talc filler and engineering plastics as an impact modifier and talc to increase the rigidity and heat distortion temperature of RPET. As a result, these blends with E-GMA exhibited significantly higher stiffness and strength especially with increasing E-GMA content. In addition, these blends with talc filler indicated the high heat distortion temperature due to the increase of the crystalinity of RPET blends. Therefore, it was found that talc played an important role in enhancing the heat resistance of RPET.
\end{abstract}

Keywords: Recycled PET; Injection Moldings; Talc; Heat Distortion Temperature

\section{Introduction}

Polyethylene terephthalate (PET) is widely used for synthetic fiber, beverage, food and other liquid container and so on, which constitutes a large portion of post consumer wastes. In the present day, the volume of the PET bottle products greatly increased. For example, the annual volume of consumption of PET drinking bottle in Japan [1] was 338,654 tons in 2000. However, in 2008, a 50\% increase in volume to 520,120 tons was recorded. Therefore, recycling of PET bottles offers a very practical solution to reduce landfill waste thus preventing environmental problems. Indeed, there are some researches [2-7] about recycled PET (RPET) injection moldings from PET bottles.

Neat PET is known to possess high elastic modulus, strength and toughness. However, recycled PET (RPET) is more susceptible to impact loadings and have lower heat distortion resistance. In order to enhance its toughness, impact modifiers are often incorporated into RPET. In our previous work, the notched impact resistance of

\footnotetext{
${ }^{*}$ Corresponding author.
}

RPET was significantly enhanced when a polyethyl-eneglycidyl-methacrylate (E-GMA) based impact modifier was incorporated [6]. However, this led to deterioration in stiffness and yield strength of the material. Furthermore, the material would deform easily even when exposed to temperatures of around $50^{\circ} \mathrm{C}$. In order to improve the stiffness and heat distortion resistance of the material, talc, which is a popular mineral filler typically used with polypropylene, was incorporated into RPET in this study. In addition, RPET blends with polybutylene-terephthalate (PBT) were prepared in order to elucidate the effect of talc filler as a nucleation of crystallization. The effects of talc loading on the heat distortion temperature, fracture behavior and static and dynamic mechanical performance of the composites were elucidated.

\section{Experimental}

\subsection{Materials}

Recycled poly (ethylene terephthalate) (RPET) was supplied by Utsumi-Recycled-Systems Co. Ltd., Japan, which 
a waste management company, while the polyeth-yleneglycidyl-methacrylate (E-GMA) impact modifier was provided by Sumitomo Chemicals Co. Ltd., Japan. Fine talc (Micro ACE series; diameter is 2.5 and $5.0 \mu \mathrm{m}$ ) was purchased from Nippon Talc Co., Ltd. and was used as the filler in RPET.

\subsection{Sample Preparation}

The sample designations and their corresponding compositions are shown in Table 1. The ratio of RPET: E-GMA was set at 84:16, which was compounded with 0 , 10, 15 and $20 \mathrm{wt} \%$ of talc in a twin screw extruder (TEX30 HSS, Japan Steel Works Co. Ltd., Japan). The barrel temperature of the extruder was set at $250^{\circ} \mathrm{C}$ $260^{\circ} \mathrm{C}$ while the screw rotation speed was $250 \mathrm{rpm}$. The blend pellets were dried by using a dehumidifying drier at $80^{\circ} \mathrm{C}$ for 5 hours prior to being injection molded (UM50, Po Yuen Co. Ltd., China) into dumbbell specimens at a barrel temperature of $280^{\circ} \mathrm{C}$ and injection speed of $100 \mathrm{~mm} / \mathrm{s}$. The dumbbell specimens will be used for mechanical, morphological and thermal characterizations.

\subsection{Characterization}

\subsubsection{Static Mechaninal Properties}

Tensile tests were performed by using an Instron 4206 universal testing machine in accordance to ASTM D638. The gauge length was $115 \mathrm{~mm}$ and the test was conducted at an extension rate of $50 \mathrm{~mm} / \mathrm{min}$. At least 5 specimens were used to ensure repeatability.

\subsubsection{Izod Impact Performance}

Notched Izod impact strength was determined for specimens notched at $2 \mathrm{~mm}$ depth $(\mathrm{a} / \mathrm{w}=0.2)$. The specimens were obtained from the parallel regions of the dumbbell specimens. The tests were conducted by using a Toyo Seiki Izod impact tester with a $5.50 \mathrm{~J}$ pendulum at $23^{\circ} \mathrm{C}$ in accordance to ASTM D256.

\subsubsection{Heat Distortion Temperature}

Heat deflection temperature (HDT) of composites was investigated according to ASTMD648 by using the dual

Table 1. Specimen designation for RPET/E-GMA/talc blends for $\phi 2.5$ and $5.0 \mu \mathrm{m}$ talc powder.

\begin{tabular}{cccc}
\hline $\begin{array}{c}\text { Specimen } \\
\text { Designation }\end{array}$ & RPET (wt\%) & $\begin{array}{c}\text { E-GMA } \\
\text { (wt\%) }\end{array}$ & Talc (wt\%) \\
\hline E16T0 & 84 & 16 & 0 \\
E16T5 & 79.8 & 15.2 & 5 \\
E16T10 & 75.6 & 14.4 & 10 \\
E16T15 & 71.4 & 13.6 & 15 \\
E16T20 & 67.2 & 12.8 & 20 \\
\hline
\end{tabular}

cantilever mode of dynamic mechanical analysis (DMA2980). The standard stress of 0.45 MPa was constantly applied onto the specimens while temperature was increased at $2^{\circ} \mathrm{C} / \mathrm{min}$ from room temperature. The changes in specimen dimension as a function of temperature was determined. The heat deflection temperature is defined as the temperature at which the specimen deflects $0.25 \mathrm{~mm}$ or $0.2 \%$ strain.

\section{Results and Discussion}

\subsection{Tensile Properties}

Figures 1 and $\mathbf{2}$ show the tensile properties of the RPET/ E-GMA/talc composites at various talc contents. The tensile modulus of the composites steadily increased with talc content due to the high rigidity of the filler [8], as could be seen in Figure 1. The tensile strength of the composites, however, was drastically reduced when 5 wt $\%$ of talc was present in the system, as shown in Figure 2. However with increasing talc content, the tensile strength of the composites was regained, especially when a smaller talc particle size was used.

\subsection{Impact Properties}

Figure 3 shows the impact strength of the RPET/EGMA/talc composites at various talc contents. With the

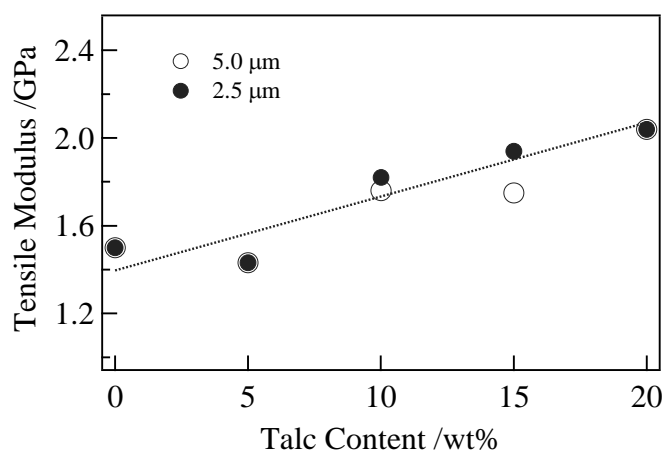

Figure 1. Effect of talc content on tensile modulus of RPET/ E-GMA/talc blends.

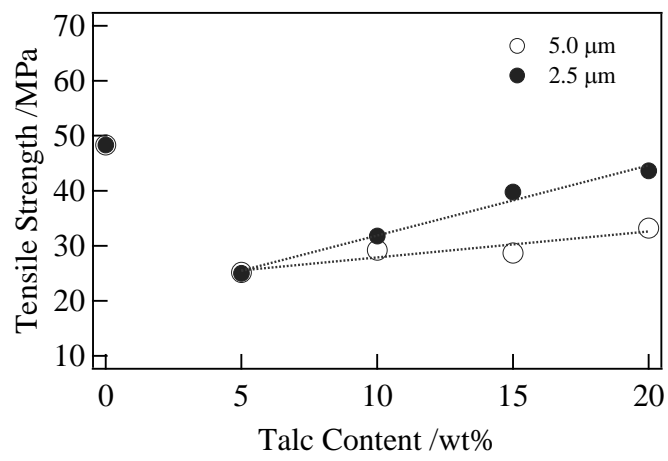

Figure 2. Effect of talc content on tensile strength of RPET/ E-GMA/talc blends. 


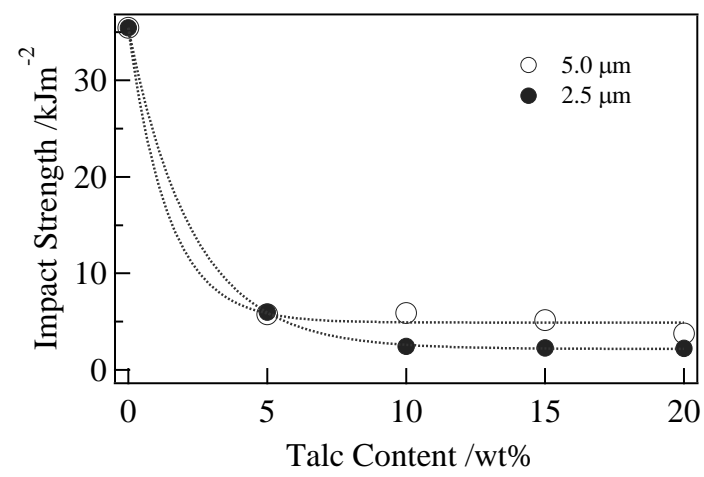

Figure 3. Izod impact strength as a function of talc content wt \% for RPET/E-GMA blends.

presence of talc, the notched impact strength of the composites drastically decreased, while similar impact performance was recorded irrespective of subsequent increments in talc content. The absence of a gradual deterioration in toughness during impact loading could be attributed to the notch sensitivity of RPET as well as the presence of micro-voids as a result of incompatibility between the matrix and talc, which acted as stress-concentration regions. Nevertheless, the notched Izod impact strength of the composites were still two times higher than that of monotonic RPET, which is attributed to the more complex crack propagation path with the presence of talc. It should also be noted that the impact properties were not affected by talc particle size, which indicates that talc is an effective stress concentrator. All unnotched specimens did not fracture upon impact, thus the results were not included in the discussion.

\subsection{Dynamic Mechanical Properties}

Figures 4 and 5 show the dynamic mechanical properties of the RPET/E-GMA/talc composites. A gradual but significant increment in storage modulus could be observed with the increment of talc content in RPET, which is in good agreement with tensile and flexural test results. With increasing temperature, the storage modulus of the composites would gradually deteriorate until around $70^{\circ} \mathrm{C}$ where a sudden loss in modulus would occur, which indicates the onset of glass transition temperature. The decreasing $\tan \delta$ peak height in Figure 5 as a function of talc content corresponds to the reduced molecular chain mobility in RPET. The usage of smaller talc particles would also result in lower $\operatorname{Tan} \delta$ peak intensities, which indicate less molecular movement and higher rigidity of the composites.

\subsection{Heat Deflection Temperature}

The heat deflection temperature (HDT) test is a popular industry standard, especially during the designing of products, which can be used as a simple comparison of

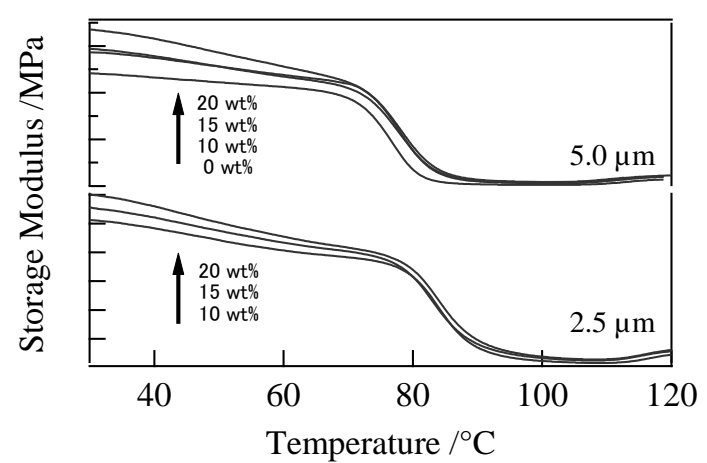

Figure 4. Storage modulus of RPET/E-GMA/talc blends.

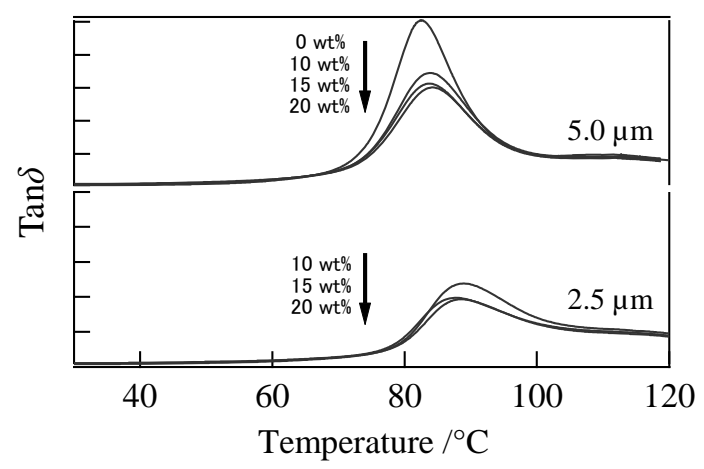

Figure 5. Tan $\delta$ of RPET/E-GMA/talc blends.

the thermal flexural stability of materials [9]. The incorporation of talc improved the heat deflection temperature (HDT) of the blends, as shown in Figure 6. HDT of the composites was increased by $38 \%$ to $85^{\circ} \mathrm{C}$ with the incorporation of $20 \mathrm{wt} \%$ talc with a particle size of $5.0 \mu \mathrm{m}$. This result suggests that the presence of talc would improve the dimensional stability of the composites by imparting resistance to molecular movement as well as inducing crystallization of RPET. The improvement in HDT would be even more pronounced when smaller (2.5 $\mu \mathrm{m})$ talc particles were incorporated into the composites. It is thought that this material could be used for the production of kitchenware such as trays, bowls or plates, which are required to withstand temperatures of up to $80^{\circ} \mathrm{C}$ such as during dish washing or sterilization. The higher HDT would also indicate that the material requires less cooling time during molding, hence reducing the cycle time during injection molding.

From above results, we indicated that talc played an important role in enhancing the crystallization and heat resistance of RPET blends. However, the amount of E-GMA was fixed at the ratio of RPET/E-GMA $=84 / 16$, and it is considered this percentage of E-GMA is excess as general injection moldings products. Therefore, we tried to investigate the mechanical and thermal properties for the lower content and smaller size of talc filler as shown in Table 2.

Figure 7 shows the results of Izod impact test for 
Table 2. Specimen designation for RPET/E-GMA/talc/PBT blends for $\phi 2.5 \mu \mathrm{m}$ talc powder.

\begin{tabular}{ccccc}
\hline $\begin{array}{c}\text { Specimen } \\
\text { Designation }\end{array}$ & $\begin{array}{c}\text { R-PET } \\
(\mathrm{wt} \%)\end{array}$ & $\begin{array}{c}\text { EGMA } \\
(\mathrm{wt} \%)\end{array}$ & $\begin{array}{c}\text { Talc } \\
(\mathrm{wt} \%)\end{array}$ & $\begin{array}{c}\text { PBT } \\
(\mathrm{wt} \%)\end{array}$ \\
\hline E3T0 & 97 & 3 & 0 & 0 \\
E3T5 & 92.1 & 2.9 & 5 & 0 \\
E3T10 & 87.3 & 2.7 & 10 & 0 \\
E3T15 & 82.5 & 2.5 & 15 & 0 \\
E3T20 & 77.6 & 2.4 & 20 & 0 \\
PBT5 & 92.1 & 2.9 & 0 & 5 \\
PBT10 & 87.3 & 2.7 & 0 & 10 \\
PBT15 & 82.5 & 2.5 & 0 & 15 \\
PBT20 & 77.6 & 2.4 & 0 & 20 \\
\hline
\end{tabular}

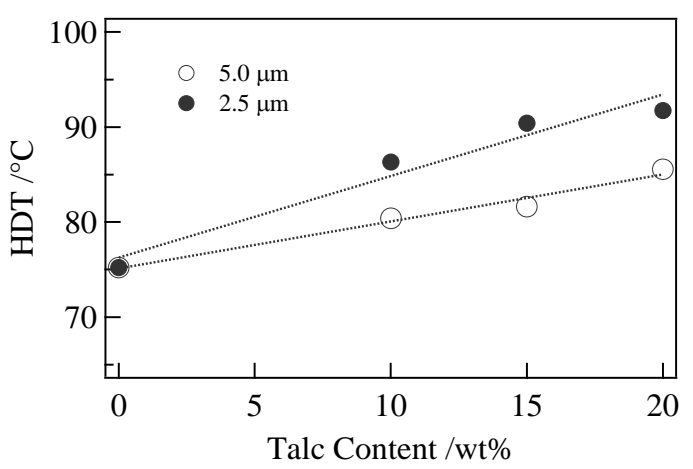

Figure 6. HDT properties for talc contents (wt\%) on RPET/ E-GMA blends.

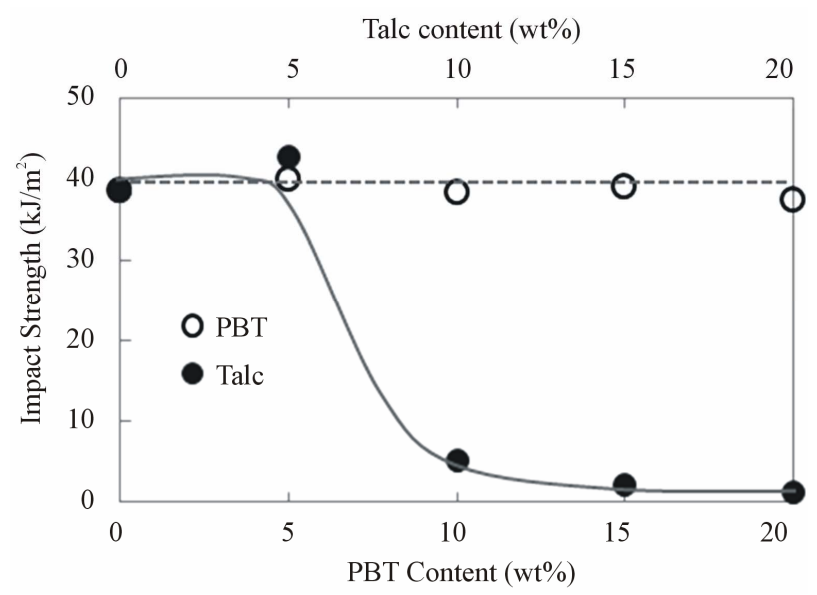

Figure 7. Izod impact strength for PBT or talc contents (wt\%) on RPET/E-GMA(3 wt\%) blends.

RPET/E-GMA/PBT and RPET/E-GMA/talc blends. In the case of RPET/E-GMA/PBT as shown in Figure 7, impact strength indicated about $40 \mathrm{~kJ} / \mathrm{m}^{2}$ and it was the constant value for each PBT content. On the other hand, in the case of RPET/E-GMA/talc blends as shown in Figure 7, impact strength was about $40 \mathrm{~kJ} / \mathrm{m}^{2}$ at 0 and 5 wt $\%$ content of talc. However, impact strength was drastically changed over $10 \mathrm{wt} \%$, it was about 2 to $5 \mathrm{~kJ} / \mathrm{m}^{2}$. This tendency was similar to the high E-GMA content results, that is, the results of Figure 3. PBT is engineering plastics and polyester, thereby, it is considered to indicate the good compatibility between PET and PBT as compared with other engineering plastics. Consequently, PBT inhibit the crystallization of PET due to protect to grow up the nucleation of lamella body. As a result, impact strength of RPET/E-GMA/PBT blends had kept the high value with increasing the PBT content. In the case of talc blends, it is considered that crystallization is increased with increasing the content of talc. However, the impact strength indicated the lower value at high content of talc, because crack or delamination is formed readily between RPET and talc filler.

Therefore, DSC measurement was performed for RPET/E-GMA/talc blends. Figure 8 shows the result of DSC curves of RPET/E-GMA/talc blends. For RPET/EGMA blends, cold-crystallization peak and melting peak were observed at $120^{\circ} \mathrm{C}$ and $250^{\circ} \mathrm{C}$, respectively. However, cold-crystallization peak was decreased with increasing the content of talc and the peak was almost never observed at $20 \mathrm{wt} \%$ talc content.

Figure 9 shows the results of HDT measurement for RPET/E-GMA/PBT and RPET/E-GMA/talc blends. As shown in Figure 9, HDT value of PBT blends was almost constant at $75^{\circ} \mathrm{C}$, on the contrary, HDT value was slightly decreased with increasing the PBT content. Therefore, it is considered that PBT component prevent PET from crystallizing. On the other hand, HDT value for RPET/E-GMA/talc blends was increased with increasing the talc content. Finally, the HDT value indicated about $170^{\circ} \mathrm{C}$ at $20 \mathrm{wt} \%$ talc content. This result will be supported by the DSC result in Figure 8. It is concluded that talc plays an important role in enhancing the crystallization and heat resistance of RPET blends and E-GMA worked so well to improve the toughness of RPET blends by optimizing the additive amount for RPET blends.

\section{Conclusion}

In this investigation, we tried to elucidate the effect of talc filler and polymer blends for RPET injection moldings. The heat deflection temperature and rigidity of RPET can be significantly enhanced with the incorporation of talc. The effects would be more pronounced if the talc particle size was smaller. However, the talc particles would cause a significant reduction in notched impact resistance, thus low talc content is recommended for the commodity composites in order to attain a balance in terms of toughness and dimensional stability. Therefore, it was found that talc played an important role in enhancing the heat resistance of RPET. 


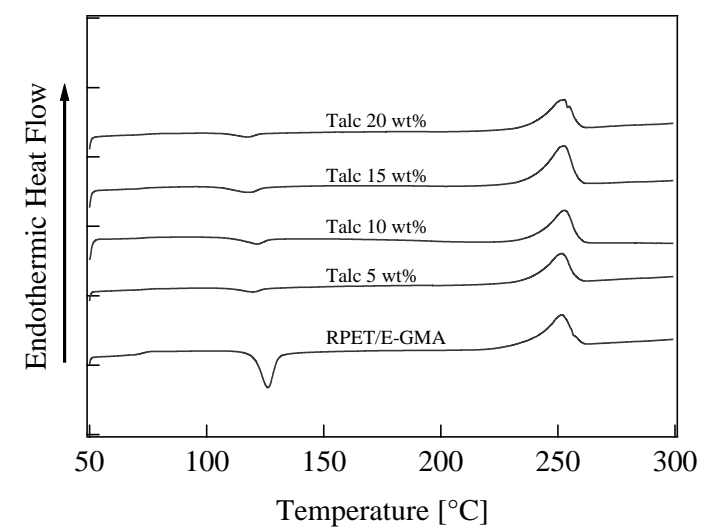

Figure 8. DSC curves of RPET/E-GMA/talc blends at various talc content.

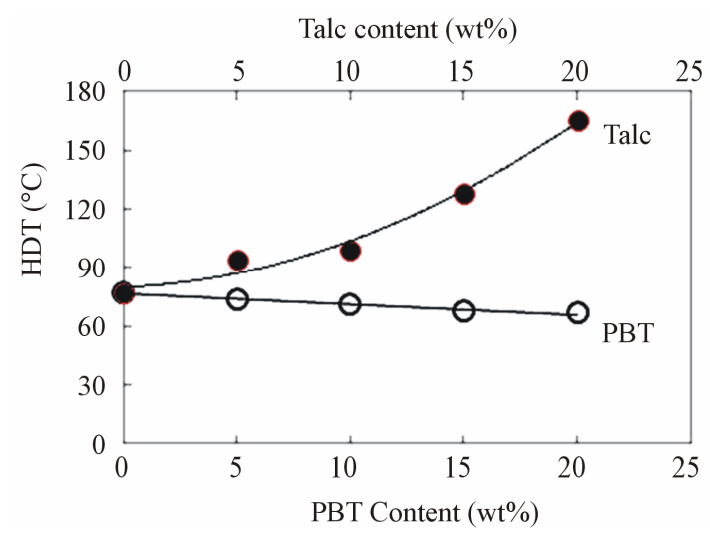

Figure 9. HDT properties for PBT or talc contents (wt\%) on RPET/E-GMA(3 wt\%) blends.

\section{Acknowledgements}

This work was partly supported by Japan Science and Technology Agency (JST), A-STEP feasibility study program (\#AS242Z01291K). We would like to express our profound gratitude to them.

\section{REFERENCES}

[1] The Council for PET Bottle Recycling, "The Trend of PET Bottle Resin Polymer in Japan,” 2009. http://www.petbottle-rec.gr.jp/english/trend.html
[2] S. Thumsorn, K. Yamada, Y. W. Leong and H. Hamada, "Thermal Decomposition Kinetic and Flame Retardancy of $\mathrm{CaCO}_{3}$ Filled Recycled Polyethylene Terephthalate/Recycled Polypropylene Blend,” Journal of Applied Polymer Science, Vol. 127, 2013, pp. 1245-1256. http://dx.doi.org/10.1002/app.37673

[3] M. Ogasahara, M. Shidou, S. Nagata, K. Yamada, Y. W. Leong and H. Hamada, "Effectiveness of High Frequency Heating on Drying and Intrinsic Viscosity Enhancement of Recycled Poly (Ethylene Terephthalate)," Journal of Applied Polymer Science, Vol. 126, 2012, pp. E166-E171. http://dx.doi.org/10.1002/app.34368

[4] S. Thumsorn, K. Yamada, Y. W. Leong and H. Hamada, "Effect of Pellet Size and Compatibilization on Thermal Decomposition Kinetic of Recycled Polyethylene Terephthalate/Recycled Polypropylene Blend,” Journal of Applied Polymer Science, Vol. 124, 2012, pp. 1605-1613. http://dx.doi.org/10.1002/app.35166

[5] S. Thumsorn, K. Yamada, Y. W. Leong and H. Hamada, "Development of Cockleshell-Derived $\mathrm{CaCO}_{3}$ for Flame Retardancy of Recycled PET/Recycled PP Blend,” Materials Sciences and Applications, Vol. 2, 2011, pp. 59-69. http://dx.doi.org/10.4236/msa.2011.22009

[6] N. Kunimune, K. Yamada, Y. W. Leong, S. Thumsorn and H. Hamada, "Influence of the Reactive Processing of Recycled Poly(Ethylene Terephthalate)/Poly (EthyleneCoglycidyl Methacrylate) Blends," Journal of Applied Polymer Science, Vol. 120, 2011, pp. 50-55. http://dx.doi.org/10.1002/app.32836

[7] R. Konishi, K. Miyata, K. Yamada, Y. W. Leong, Y. Hashimoto and H. Hamada, "Interface of Draw Ratio on Adhesion of Heat-sealed Recycled-PET Films,” Journal of Packaging Science and Technology, Vol. 20, No. 2, 2011, pp.107-115.

[8] Y. Yand, C. G'Sell, J. Hiver and S. Bai, "Dynamic Mechanical Properties and Morphology of High-Density Polyethylene/ $\mathrm{CaCO}_{3}$ Blends with and without an Impact Modifier," Journal of Applied Polymer Science, Vol. 103, 2007, pp. 3907-3914.

http://dx.doi.org/10.1002/app.25619

[9] B. Alcock, N. O. Cabrera, N.-M. Barkoula, C. T. Reynolds, L. E. Govaert and T. Peijs, "The Effect of Temperature and Strain Rate on the Mechanical Properties of Highly Oriented Polypropylene Tapes and All-Polypropylene Composites," Composites Science and Technology, Vol. 67, 2007, pp. 2061-2070.

http://dx.doi.org/10.1016/j.compscitech.2006.11.012 